\title{
In vivo study of the caecal fermentation in the post-weaned and adult rabbit
}

\author{
R Bellier, T Gidenne
}

INRA, Station de Recherches Cunicoles, BP 27, 31326 Castanet-Tolosan, France

Compared with the adult rabbit, the post-weaned animal is particularly affected by digestive disorders, possibly generated by modifications of caecal fermentative activity (CFA). The in vivo CFA of adult rabbits was thus compared with that of 6 week-old animals.

Six adult and 6 post-weaned rabbits, receiving ad libitum a standard pelleted diet $(17 \%$ crude protein and $30 \%$ NDF) were cannulated on the caecum using a glass cannula (Gidenne and Bellier, 1992). To prevent an effect of sampling time, 12 in vivo caecal digesta collections were performed individually every $2 \mathrm{~h}$ in order to cover 24 $h$, for 6 consecutive days.

The dry matter (DM) level of the caecal digesta sampled in the 6-week-old animals was lower $(3 \%)$ than that of the adult, and the total volatile fatty acids (VFA) concentration expressed on a DM basis did not differ significantly according to age. However, the VFA level expressed on a fresh matter basis (mM/L) was lower $(24 \%)$ in the young than the adult. Inversely higher levels of ammonia $\left(\mathrm{NH}_{3}\right)$ were measured in the young, but no significant variations in caecal $\mathrm{pH}$ were observed. The acetate (C2) and butyrate (C4) concentrations in the young rabbit were 40 and $22 \%$ lower, respectively, than those of the adult. The C4 molar proportion was significantly lower in the young than the adults, and there was no change in the propionate (C3) molar proportions according to age (see table I). These differences in CFA between young and adult animals could be explained by an adaptation of caecal flora related to consumption of dry feed and also the establishment of caecotrophy during the post-weaning period.

Gidenne T, Bellier R (1992) Repr Nutr Develop 32, 365-376

Table I. Composition of caecal digesta in post-weaned and adult rabbits.

\begin{tabular}{lcccccccc}
\hline Age & $D M(\%)$ & $p H$ & $N_{3}(m M / L)$ & $\begin{array}{c}\text { Total } V F A \\
(m M / L)\end{array}$ & $C 2(\% M / g D M)$ & $C 3(\%)$ & $C 4(\%)$ \\
\hline 6-week-old & 17.6 & 6.0 & 7.6 & 65.4 & 383 & 83.2 & 5.4 & 10.0 \\
Adult & 20.3 & 5.9 & 6.1 & 86.1 & 428 & 80.8 & 5.2 & 13.0 \\
SEM & 0.21 & 0.03 & 0.26 & 2.06 & 11.95 & 0.29 & 0.14 & 0.23 \\
$P<$ & 0.0007 & 0.20 & 0.02 & 0.0008 & 0.31 & 0.07 & 0.62 & 0.004 \\
\hline
\end{tabular}

